\title{
Premarket Device Application
}

National Cancer Institute

\section{Source}

National Cancer Institute. Premarket Device Application. NCI Thesaurus. Code C80441.

A premarket submission made to FDA to review and evaluate the safety and effectiveness of a Class III medical device. 